\title{
Teknologi Geolocation Berbasis Android dengan Metode K-Means untuk Pemetaan UMKM di Kabupaten Jepara
}

\author{
Noor Azizah*, Nur Aeni Widiastuti \\ Program Studi Sistem Informasi, Universitas Islam Nahdlatul Ulama Jepara \\ Naskah Diterima : 16 Juli 2018; Diterima Publikasi : 10 September 2018 \\ DOI : 10.21456/vol8iss2pp214-225
}

\begin{abstract}
Micro, Small and Medium Enterprises (MSMEs) are industrial sectors that are very important to sustain the economy of Jepara Regency. There are 18,695 Small and Medium Enterprises (SMEs) in Jepara Regency in 2016, including wood carving, troso weaving, chopper brass (monel) jewelry, sculpture, rattan crafts, calligraphy, and reliefs. The number of SMEs in Jepara makes buyers or tourists have many choices in buying products of varying quality and competitive prices. In addition, sometimes they are also confused in finding the location of SMEs. Therefore, this application is made to solve these problems by making an application that provides location-based information center industrial services. This application is expected to facilitate tourists in finding the location of the industry to be addressed.Geolocation technology is used to identify real-world geographic locations that can be applied to the Android operating system. So this application provides store description services, product photos, and maps. SMEs are presented in the application in the map using the k-mean algorithm. The parameters used are the type of industry, number of employees, turnover per year, tools used. For the clustering have 3 categories, there are namely small, medium and large. The advantages of this algorithm can group data according to the similarity of data used in one group and minimize the same data between groups and cannot process data that is a missing value.
\end{abstract}

Keywords :GeolocationTechnology; K-MeansClustering; Android; MSME.

\begin{abstract}
Abstrak
Usaha Mikro Kecil Menengah (UMKM) adalah sektor industri yang sangat penting untuk menopang perekonomian Kabupaten Jepara. Terdapat 18.695 Usaha Kecil Menengah (UKM) di Kabupaten Jepara pada tahun 2016, diantaranya seni ukir kayu, tenun ikat troso, perhiasan monel, patung, kerajinan rotan, kaligrafi, dan relief. Banyaknya UKM di Jepara membuat pembeli atau wisatawan memiliki banyak pilihan dalam membeli produk dengan kualitas yang beragam dan harga yang kompetitif. Selain itu, terkadang mereka juga bingung dalam mencari lokasi UKM. Oleh sebab itu, aplikasi ini dibuat untuk menyelesaikan permasalahan tersebut dengan pembuatan aplikasi yang memberikan layanan informasi sentra industri berbasis lokasi.Dengan aplikasi ini diharapkan dapat mempermudah wisatawan dalam mencari lokasi industri yang akan dituju.Metode pengembangan sistem menggunakan metode waterfall.Teknologi geolokasi digunakan untuk mengidentifikasi lokasi geografis dunia nyata yang dapat diterapkan ke sistem operasi android. Sehingga aplikasi ini memberikan layanan deskripsi toko, foto produk, dan peta. UKM yang disajikan dalam aplikasi di petakan dengan menggunakan algoritma kmean.Parameter yang digunakan adalah omset per tahun, aset, dan alat yang digunakan. Untuk kategori pengclusterannya ada 3 yaitu mikro,kecil dan menengah. Kelebihan dari algoritma ini dapat mengelompokkan data sesuai dengan kemiripan data yang digunakan dalam satu grup dan meminimalkan data yang sama antar kelompok serta tidak dapat memproses data yang missing value.
\end{abstract}

Kata kunci:Geolokasi; Metode K-MeansClustering; Android; UMKM

\section{Pendahuluan}

Kabupaten Jepara memiliki banyak potensi daerah mulai dari industri mebel, kain tenun ikat troso, kerajinan monel, patung ukir, kaligrafi, relief dan kuliner daerah sampai dengan obyek wisata. Banyaknya potensi yang ada menimbulkan munculnya usaha mikro, kecil dan menengah (UMKM). Menurut Badan Pusat Statistik Kabupaten

*) Penulis korespondensi: azizah@unisnu.ac.id
Jepara (2015) terdapat 18.695 Usaha Kecil Menengah (UKM).(diakses pada tanggal $09 \mathrm{Mei}$ 2017)

Dari tahun ke tahun UMKM yang ada di Jepara mulai berkembang. Pemasaran yang dilakukan UMKM cukup luas, mulai dari kota - kota diseluruh Indonesia bahkan ke luar negeri. Dengan banyaknya jumlah sentra industri yang ada membuat para pembeli mempunyai banyak pilihan dalam membeli 
suatu produk dengan kualitas beragam dan harga yang bersaing. Namun yang menjadi permasalahan terkadang pembeli atau wisatawan yang datang ke Jepara bingung dengan lokasi kerajinan yang ingin dicari dikarenakan banyaknya UMKM yang ada.

Geolocation merupakan proses mendeteksi lokasi keberadaan kita menggunakan koneksi internet berdasarkan titik koordinat longitude dan latitude. Dengan geolocation kita juga dapat menampilkan pencarian rute sebagai informasi yang penting bagi pengguna dalam melakukan perjalanan. (Anwar et al.. ,2015)

Dari beberapa penelitian terdahulu teknologi geolocation diterapkan di layanan website untuk pemetaan UMKM industri tenun di Garut. (Harwati, et al.., 2015). Kemudian penggunaan teknologi geolocation untuk monitoring dan pemetaan UMKM sektor informal kota Malang dan belum menggunakan algoritma clustering. (Kurniawan, 2016)

Seiring dengan perkembangan teknologi berpengaruh terhadap perkembangan sistem informasi dan penggunaan teknologi sistem informasi yang semakin memasyarakat. Seperti diketahui perkembangan teknologi informasi yang berbasis mobile lebih disukai dan dapat memenuhi kebutuhan akan informasi yang cepat, murah dan efisien. Oleh sebab itu, peneliti mengusulkan untuk pengklasteran UMKM dengan algoritma $k$-means yang diterapkan pada aplikasi android yang bersifat mobile. Sehingga mudah di akses dimana saja dan kapan saja selama terkoneksi dengan jaringan intenet. Tujuan dari penelitian ini adalah dengan adanya sistem informasi geografis berbasis android untuk pemetaaan UMKM di Jepara dapat mempermudah wisatawan dalam pencarian sentra industri yang dituju dikarenakan banyaknya sentra industri kerajinan yang ada.

Penelitian ini akan membahas tentang pemetaan UMKM yang ada di Jepara berbasis geolocation dengan android yang akan memberikan informasi tentang lokasi sentra industri yang dicari dan deskripsi dari sentra industri tersebut. Metode yang digunakan untuk pengelompokkan UMKM menggunakan metode KMeans karena memiliki kelebihan yaitu dapat mengelompokkan data sesuai dengan kemiripan data yang digunakan dalam satu kelompok, meminimalkan kemiripin data antar kelompok dan tidak dapat memproses data yang missing value.

\section{Kerangka Teori}

\subsection{Geolocation}

Geolocation adalah identifikasi lokasi geografis suatu objek pada dunia nyata. Geolocation mempunyai kaitan erat dengan positioning, perbedaannya adalah geolocation lebih spesifik dalam menentukan sebuah lokasi (misalnya alamat jalan) dibandingkan dengan positioning yang hanya mencakup sekumpulan koordinat geografis. Suatu lokasi geografis mengandung nilai latitude dan longitude.(Anwar et al..,2015)

Adapun konsep dari geolocation seperti pada gambar 1 :

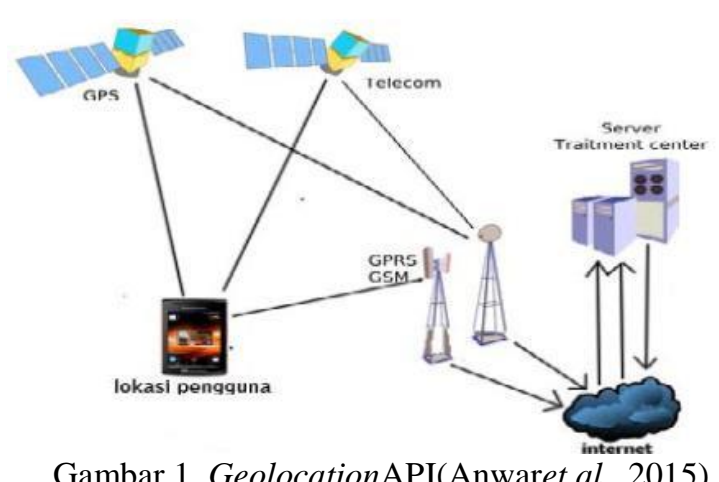

\subsection{Metode K-Means}

Clustering merupakan suatu metode untuk mencari dan mengelompokkan data yang memiliki kemiripan karakteristik antara satu data dengan data yang lain. K-Means clustering merupakan salah satu metode data clustering non-hirarki yang mengelompokan data dalam bentuk satu atau lebih cluster atau kelompok. Data- data yang memiliki karakteristik yang sama dikelompokan dalam satu cluster atau kelompok dan data yang memiliki karakteristik yang berbeda dikelompokan dengan cluster atau kelompok yang lain sehingga data yang berada dalam satu cluster atau kelompok memiliki tingkat variasi yang kecil (Ong, 2013). Menurut Harwati (2015) Cara kerja algoritma k-means adalah mengungkapkan pola tersembunyi dan membentuk pola sesuai dengan kategori cluster yang diberikan.

Langkah-Langkah clustering dengan K-Means adalah sebagai berikut (Santoso, 2007) :

1) Pilih jumlah cluster $k$.

2) Inisialisasi $k$ pusat cluster ini bisa dilakukan dengan berbagai cara. Namun yang paling sering dilakukan adalah dengan cara random.

3) Dalam tahap ini perlu dihitung jarak tiap data ke tiap pusat cluster. Jarak paling antara satu data dengan satu cluster tertentu akan menentukan suatu data masuk dalam cluster mana. teori jarak Euclidean yang dirumuskan sebagai berikut:

$$
\begin{aligned}
& D_{\left(I_{i j}\right)}=\sqrt{\left(X_{1 i}-X_{1 j}\right)^{2}}+\left(X_{2 i}-\right. \\
& X_{2 j}+\cdots+\left(-X_{k}\right)^{2}
\end{aligned}
$$

Keterangan :

$\mathrm{D}(\mathrm{i}, \mathrm{j})=$ Jarak data ke $\mathrm{i}$ ke pusat cluster $\mathrm{j}$

$X_{k}=$ Data ke i pada atribut data ke $\mathrm{k}$

$X_{k}=$ Titik pusat ke $\mathrm{j}$ pada atribut ke $\mathrm{k}$

4) Hitung kembali pusat cluster dengan keanggotaan cluster yang sekarang. Pusat cluster adalah rata- 
rata dari semua data/ objek dalam cluster tertentu. Jika dikehendaki bisa juga menggunakan median dari cluster tersebut. Jadi rata-rata (mean) bukan satu-satunya ukuran yang bisa dipakai.

5) Tugaskan lagi setiap objek memakai pusat cluster yang baru. Jika pusat cluster tidak berubah lagi maka proses clustering selesai. Atau, kembali ke langkah nomor 3 sampai pusat cluster tidak berubah lagi.

Algoritma K-Means clustering dapat digambarkan dalam bentuk flowchart seperti pada gambar 2 :

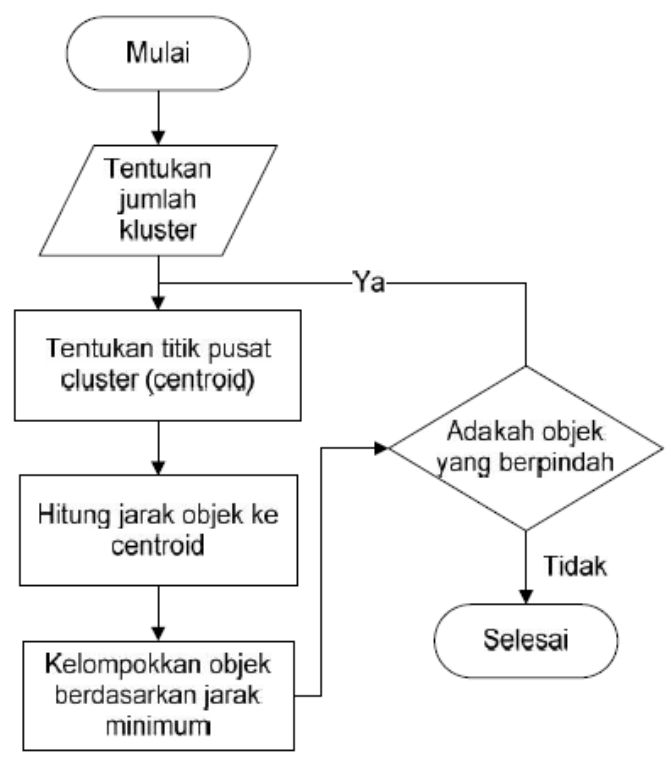

Gambar 2. Algoritma K-Means Clustering (Wakhidah,2010)

Pada penelitian ini pemetaan atau pengclusteran UMKM yang akan di clusterkan berdasarkan sentra industri furniture kayu, kerajinan rotan, tenun troso, monel, gerabah dan genteng. Yang akan diklasterkan ke dalam 3 kategori yaitu mikro,kecil,dan menengah.

\section{Metode}

\subsection{Tahapan}

Pengembangan aplikasi geolocation ini menggunakan pendekatan model waterfall. Sedangkan Metode Pengumpulan data. menggunakan metode studi pustaka, observasi, wawancara dan dokumentasi.

Model Waterfall merupakan model yang paling populer dan sering dianggap sebagai pendekatan klasik dalam daur hidup pengembangan sistem. Pada metode waterfall terdapat 6 tahapan seperti yang digambarkan pada Gambar 3, yaitu: analysis, requirements specification, design, implementation, testing and integration, operation and maintenance.

Kelebihan dari tahapan ini adalah seorang programmer bisa merancang sistem secara urut dan ketika ada perbaikan bisa langsung menuju tahapan yang diperbaiki tanpa harus dimulai dari awal.

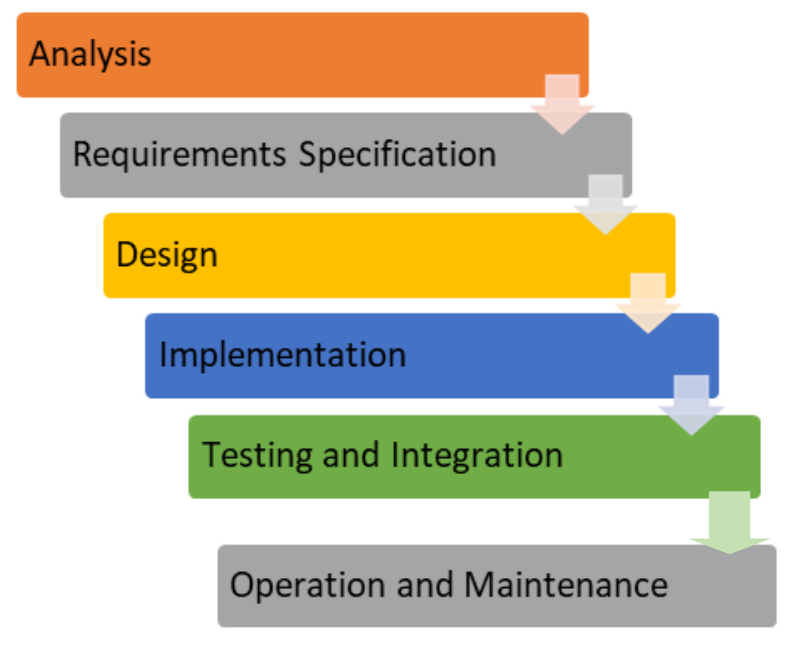

Gambar 3. Tahapan model waterfall

(Pascaprahastyan et al., 2015)

\subsection{Analisis}

Pada tahap ini dilakukan analisa terhadap objek penelitian. Kegiatan yang dilakukan adalah:

1) Analisis kebutuhan data dan informasi

Menganalisis data apa saja yang diperlukan dan informasi apa saja yang akan dihasilkan dari pengolahan data yang ada. Selain itu juga menganalisis kebutuhan software yang digunakan untuk membuat permodelan serta membangun sistem.

\section{2) Analisis kebutuhan sistem}

Menganalisis dalam rangka pembangunan aplikasi pemetaan UMKM dengan memanfaatkan geolocation, adapun kegiatan yang dilakukan pada tahap ini adalah :

a. Mengidentifikasi masalah yang ada pada proses pemetaan UMKM

b. Mengidentifikasi kebutuhan teknologi informasi untuk pemetaan UMKM sesuai dengan cluster industrinya

c. Memberikan alternatif teknologi untuk pemetaan UMKM berdasarkan cluster industri, pada bagian ini berisi segala kebutuhan yang diperlukan baik software, hardware dan sumber daya manusia.

\subsection{Perancangan}

Perancangan sistem merupakan tahapan inti dari sebuah rancang bangun sebuah proses. Pada tahap ini dilakukan penyusunan rancang bangun aplikasi geolocation menggunakan metode K-Means untuk pemetaan. Perancangan sistem ini, berfokus pada bagaimana merancang sebuah struktur data di dalam sistem, arsitektur perangkat lunak, representasi antarmuka, dan detail (algoritma) Procedural. 


\subsection{Implementasi}

Merupakan tahapan yang dilakukan untuk menyelesaikan desain sistem yang sudah dirancang. Dalam hal ini dilakukan pembuatan aplikasi geolocation menggunakan perangkat android.

\subsection{Pengujian}

Setelah aplikasi selesai dibangun, maka tahapan berikutnya adalah pengujian black box testing.

\subsection{Perawatan}

Perawatan terhadap sistem juga dilakukan setelah aplikasi tersebut dapat dijalankan. Tujuannya adalah agar aplikasi geolocation tersebut selalu up to date terhadap penambahan data.

\section{Hasil dan Pembahasan}

Tahap awal dalam penelitian ini yang dilakukan adalah melakukan pengumpulan data ke sentra yang ada di Jepara dan mendaftarkan lokasinya ke google map. Sentra yang dijadikan objek penelitian yaitu sentra genteng dan gerabah, sentra monel, sentra rotan, sentra kain tenun troso, sentra mebel. Hasil pengumpulan data dapat dilihat pada tabel 1 .

Tabel 1. Nama dan Jumlah data sentra UMKM

\begin{tabular}{lc}
\hline \multicolumn{1}{c}{ Nama Sentra } & Jumlah Industri \\
\hline Gerabah dan genteng & 30 \\
Monel & 13 \\
Rotan & 16 \\
Kain Tenun Troso & 20 \\
Mebel & 30 \\
\hline Total & 109 \\
\hline
\end{tabular}

Setelah pengumpulan data kemudian pemetaan UMKM dengan metode K-Means Cluster dengan tools Microsoft Excel. Dengan menggunakan microsft Excel lebih mudah dibandingkan dengan menggunakan tool Rapidminer. Dan output yang dihasilkan lebih mudah dibaca dengan excel serta rumus Euclideanbisa diterapkan disini.Parameter yang digunakan : Omset /Tahun,Aset,dan alat produksi. Kategori cluster dibagi menjadi 3 yaitu: mikro, kecil menengah. Akan tetapi untuk kasus industri mikro seperti industri gerabah dan genteng, monel yang masuk ke dalam kategori mikro kami sub kan ke dalam skala besar, menengah, kecil. Hasil dari penelitian ini dapat disimpulkan bahwa parameter memegang peran penting untuk penentuan cluster. Semakin banyak parameter dan rule/aturan yang diterapkan akan mempercepat pembentukan cluster. Begitu juga dengan jumlah dataset yang diolah semakin banyak akan semakin bagus. Kelebihan dari algoritma ini adalah mempermudah pengelompokkan data berdasarkan kemiripan data, meminimalisir data yang duplikat. Data yang diperoleh diinputkan di microsoft excel kemudian rumus Euclidean dimasukkan dan diproses. Sehingga menghasilkan data hasil pemetaan UMKM.Contoh tabel hasil analisa dapat dilihat pada Tabel 2. Pemetaan industri genteng.

\begin{tabular}{|c|c|c|c|c|c|}
\hline NO & NAMA & $\begin{array}{l}\text { OMSET } \\
\text { /BULAN }\end{array}$ & ASET & $\begin{array}{l}\text { ALAT } \\
\text { 'MANU } \\
\text { AL }\end{array}$ & CLUSTER \\
\hline 1 & MUHTAROM & 150000000 & 43500000 & 1 & KECIL \\
\hline 2 & SUHARTO & 300000000 & 111000000 & 1 & BESAR \\
\hline 3 & DARSONO & 180000000 & 43500000 & 1 & KECIL \\
\hline 4 & $\begin{array}{l}\text { MAHKOTA } \\
\text { AKSESORIS }\end{array}$ & 258000000 & 111000000 & 1 & KECIL \\
\hline 5 & SUROTO & 168000000 & 43500000 & 1 & KECIL \\
\hline 6 & SUGIRI & 186000000 & 43500000 & 1 & KECIL \\
\hline 7 & SUTAMAM & 174000000 & 43500000 & 1 & KECIL \\
\hline 8 & $\begin{array}{l}\text { EKO } \\
\text { SUPOYO }\end{array}$ & 162000000 & 43500000 & 1 & KECIL \\
\hline 9 & $\begin{array}{l}\text { M. ABDUL } \\
\text { BASIR }\end{array}$ & 168000000 & 43500000 & 1 & KECIL \\
\hline 10 & SUMARDI & 162000000 & 43500000 & 1 & KECIL \\
\hline 11 & $\begin{array}{l}\text { OMAH } \\
\text { GENTENG } \\
\text { BERKAH }\end{array}$ & 240000000 & 111000000 & 1 & KECIL \\
\hline 12 & $\begin{array}{l}\text { BUMI } \\
\text { GENTENG } \\
\text { JEPARA }\end{array}$ & 222000000 & 111000000 & 1 & KECIL \\
\hline 13 & $\begin{array}{l}\text { ARIPIN } \\
\text { GENTENG }\end{array}$ & 198000000 & 43500000 & 1 & KECIL \\
\hline 14 & $\begin{array}{l}\text { GENTENG } 3 \\
\text { PUTRA } \\
\text { UD }\end{array}$ & 204000000 & 111000000 & 1 & KECIL \\
\hline 15 & $\begin{array}{l}\text { ANAMBAS } \\
\text { PUTRA }\end{array}$ & 168000000 & 43500000 & 1 & KECIL \\
\hline
\end{tabular}

Selain pada industri genteng pada industri gerabah ketika di clusterkan menghasilkan cluster seperti tabel 3. Dikarenakan data yang diperoleh kebanyakan pengrajin memiliki omset dan aset sedikit sehingga masuk ke dalam cluster mikro-kecil.

Tabel 3. Pemetaan Industri Gerabah

\begin{tabular}{|c|c|c|c|c|c|}
\hline NO & NAMA & $\begin{array}{c}\text { OMSET } \\
\text { /TAHUN }\end{array}$ & ASET & $\begin{array}{c}\text { ALAT/ } \\
\text { MANUAL }\end{array}$ & $\begin{array}{c}\text { CLUS } \\
\text { TER }\end{array}$ \\
\hline 1 & $\begin{array}{l}\text { KASTURI } \\
\text { KERAMIK } \\
\text { (KS Keramik) }\end{array}$ & 54000000 & 21000000 & 1 & KECIL \\
\hline 2 & RUMIYATI & 54000000 & 20000000 & 1 & KECIL \\
\hline 3 & $\begin{array}{l}\text { MI'UN } \\
\text { (GERABAH } \\
\text { PAK MI'UN) }\end{array}$ & 60000000 & 30000000 & 1 & KECIL \\
\hline 4 & MUSTIAN & 60000000 & 21000000 & 1 & KECIL \\
\hline 5 & $\begin{array}{l}\text { KHARISMA } \\
\text { GERABAH }\end{array}$ & 60000000 & 21000000 & 1 & KECIL \\
\hline 6 & SRI MURNI & 60000000 & 30000000 & 1 & KECIL \\
\hline 7 & SUTINI & 60000000 & 25000000 & 1 & KECIL \\
\hline 8 & MASRIPAH & 66000000 & 25000000 & 1 & KECIL \\
\hline 9 & $\begin{array}{l}\text { ANIS } \\
\text { HARTONO }\end{array}$ & 72000000 & 35000000 & 1 & KECIL \\
\hline
\end{tabular}




\begin{tabular}{llrccc}
\hline NO & NAMA & $\begin{array}{r}\text { OMSET } \\
\text { /TAHUN }\end{array}$ & ASET & $\begin{array}{c}\text { ALAT/ } \\
\text { MANUAL }\end{array}$ & $\begin{array}{c}\text { CLUS } \\
\text { TER }\end{array}$ \\
\hline 10 & SURIPAH & 78000000 & 30000000 & 1 & KECIL \\
11 & SUKINI & 78000000 & 30000000 & 1 & KECIL \\
12 & TUMINAH & 90000000 & 25000000 & 1 & KECIL \\
13 & RATENI & 96000000 & 30000000 & 1 & KECIL \\
14 & KARMISEH & 96000000 & 40000000 & 1 & KECIL \\
15 & KARSEH & 234000000 & 50000000 & 1 & KECIL \\
\hline
\end{tabular}

Hasil dari pemetaan kemudian dibuatkan perancangan aplikasi androidnya. Denganmetode waterfalltahapan perancangan aplikasi UMKM dapat dilihat pada gambar 4.

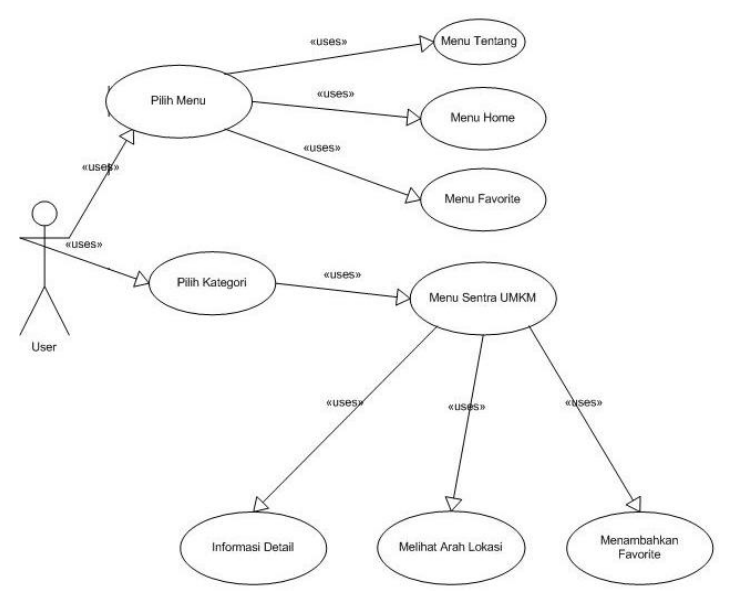

Gambar 4. Diagram Pengguna aplikasi UMKM

Setelah tahapan perancangan kemudian coding dan hasil. Berikut tampilan hasil dari aplikasi UMKM. Tampilan Gambar 5 adalah Peta dan Marker Lokasi yang terhubung dengan Google Map yang bisa menampilkan jarak lokasi UMKM tersebut.

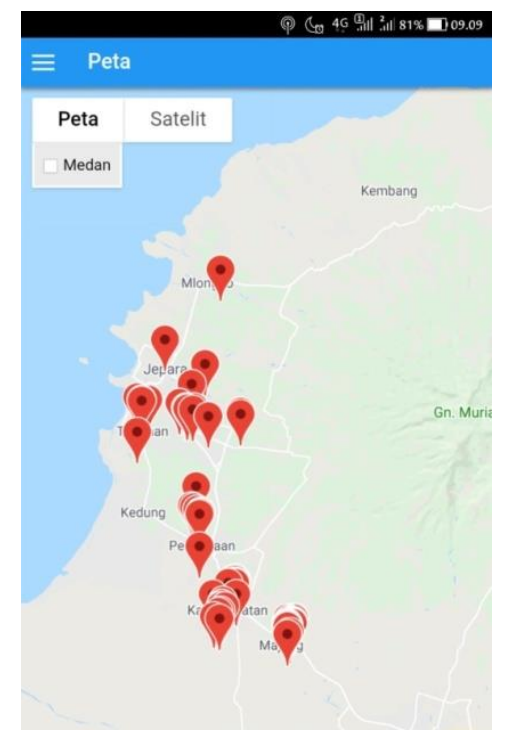

Gambar 5. Tampilan Peta dan Marker Lokasi
Tampilan halaman menu utama (Gambar 6), merupakan tampilan setelah splash screen selesai. Halaman utama ini merupakan bagian awal dari aplikasi yang menampilkan pilihan kategori pada UMKM tersebut.

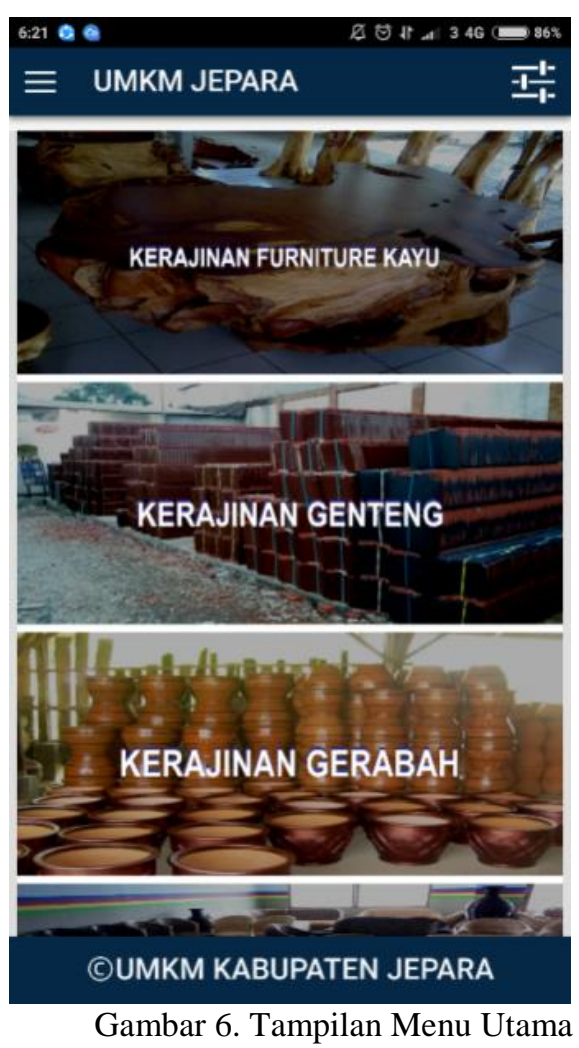

Tampilan isi kategori (Gambar 7), merupakan tampilan setelah memilih salah satu kategori UMKM, dimana user memilih UMKM yang akan dikunjungi.

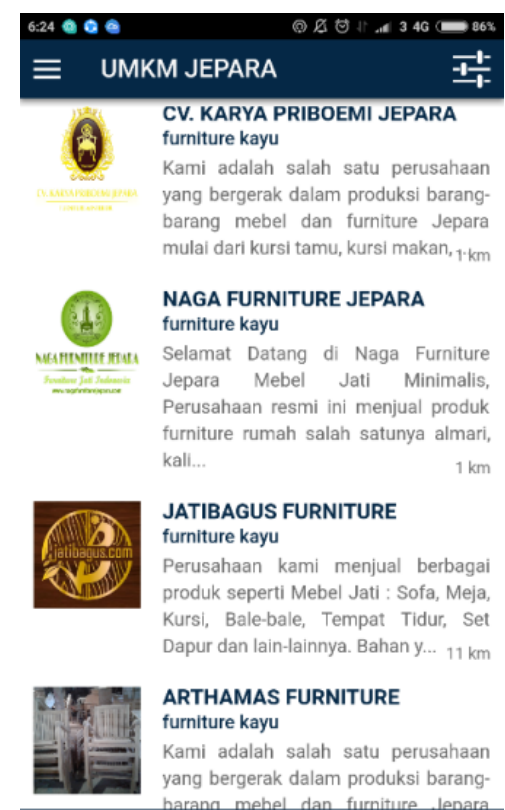

CUMKM KABUPATEN JEPARA

Gambar 7. Tampilan isi kategori 
Tampilan pencarian lokasi ini untuk user dapat mengetahui jarak tempuh dari lokasi user sampai ke tempat lokasi UMKM tersebut (Gambar 8).

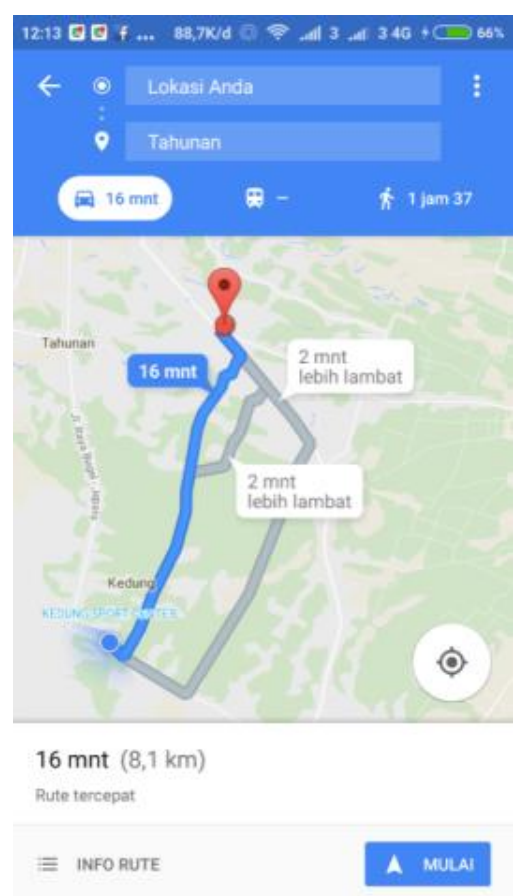

Gambar 8. Tampilan pencarian lokasi

Tampilan di Gambar 9 adalah tampilan halaman informasi detail yang merupakan tampilan setelah memilih halaman lokasi. Di dalam ini user dapat informasi secara singkat dan jelas.

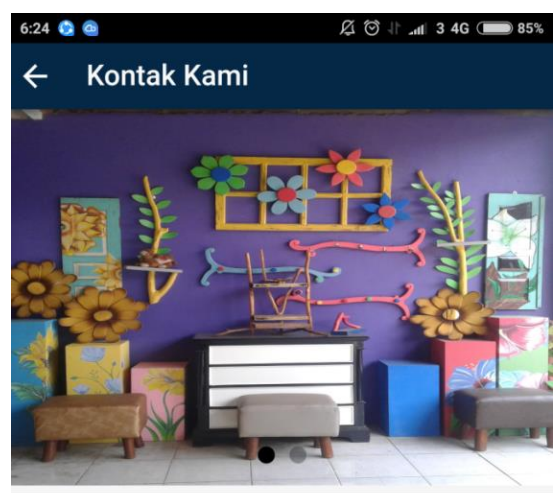

BINTANG SEJATI FURNITURE

JL. Bok Biru RT 02/04 Tahunan Jepara

Deskripsi Lokasi

Kami adalah salah satu perusahaan yang bergerak dalam produksi barang-barang mebel dan furniture Jepara mulai dari kursi tamu, kursi makan, meja makan, set kursi meja makan, almari, bufet, sketsel, jam hias, tolet/ meja rias, gebyok, depan/ tempat tidur, nakas, mimbar, kaligrafi, relief, handicraft, souvenir dan patung ukir. Selain produk yang kami tawarkan, kami juga menerima pesanan model lain

Gambar 9. Tampilan sentra industri mebel
Tampilan gambar 10 diatas adalah halaman pencarian berdasarkan jarak atau nama di mana user dapat secara bebas mencari UMKM berdasrkan jarak tempuh atau nama UMKM tersebut.

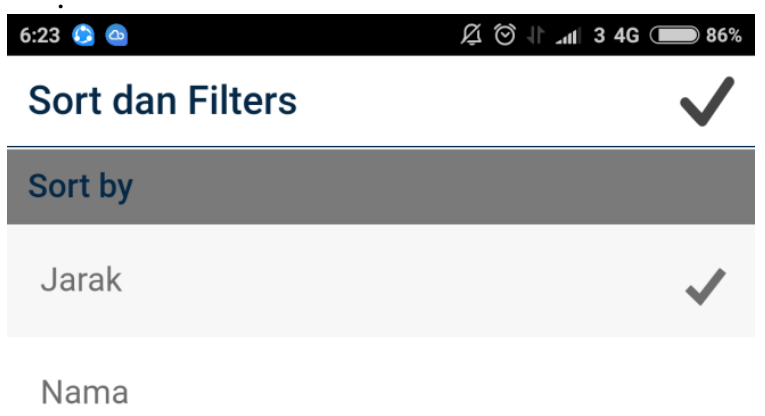

Gambar 10. Tampilan pencarian berdasarkan jarak dan nama

Tampilan halaman review ini adalah tempat user untuk memberikan komentar berupa kritik dan saran kepada UMKM yang sudah dikunjungi (Gambar 11).

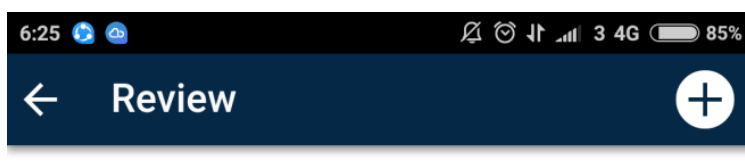

Hasan

Bermanfaat untuk memberikan informasi

7/8/18 6:25 AM

$\star \star \star \star \star$

Gambar 11. Tampilan Review dari pengunjung

Hasil dari penelitian ini menghasilkan pemetaan UMKM berdasarkan cluster yang sudah ditetapkan yaitu mikro, kecil, menengah dan diterapkan dalam aplikasi pemetaan UMKM yang ditujukan kepada wisatawan pada umumnya dan penduduk Jepara pada khususnya untuk mempermudah dalam pencarian sentra industri yang ada.

Untuk cluster secara umum dibagi kedalam 3 kategori yaitu mikro,kecil,menengah. Sedangkan, untuk sentra industri gerabah, genteng, dan monel yang masuk kedalam cluster mikro dibagi kembali menjadi 3 yaitu mikro-kecil, mikro-sedang dan mikro-tinggi. Hal ini dilakukan untuk mensiati agar data bisa seimbang. Ketika data sudah diolah dengan algoritma k-means kemudian dimasukkan ke dalam aplikasinya. Sehingga pembuatan aplikasi ini bisa dikatakan valid karena data yang dihasilkan sudah diolah dan kemudian aplikasinya juga sudah melalui tahapan pengujian aplikasi yaitu blackbox testing. Jika dibandingkan dengan penelitian sebelumnya yang dilakukan oleh Wulandari dan Noveandini (2015) dan Kurniawan (2016) yang hanya 
menampilkan peta lokasi industri itu saja pada aplikasi ini lebih praktis bersifat open source dan bisa didownload di playstore serta mudah untuk digunakan dalam penggunaannya selama terkoneksi dengan jaringan internet dan informasi yang disajikan lebih detail dari segi deskripsi toko, tampilan produk, peta dan user bisa memberikan komentar dikolom komentar.

Pengujian black box testing digunakan untuk pengujian aplikasi yang divalidasi oleh ahlinya. Dari hasil pengujian dengan pembagian kuesioner diperoleh 96,4 \% dan responden 85,9\%.yang menyatakan aplikasi ini layak untuk digunakan.

\section{Kesimpulan}

Penelitian ini membahas tentang permasalahan wisatawan yang kesulitan dalam mencari sentra industri yang ada di Jepara. Terdapat sejumlah 1.869 UKM yang tersebar. Sehingga aplikasi ini dibuat untuk menyelesaikan permasalahan tersebut dengan pembuatan aplikasi yang memberikan layanan informasi sentra industri berbasis lokasi.Diharapkan dapat mempermudah wisatawan dalam mencari lokasi industri yang akan dituju.

Data yang diperoleh dilapangan sejumlah 109 sentra industri kemudian dipetakan menjadi 3 yaitu mikro,kecil, menengah menggunakan algoritma kmean.Kelebihan dari algoritma ini adalah dapatmengelompokkandatasesuaidengankemiripanda tayang digunakandalam satu kelompok , meminimalkan kemiripin dataantarkelompok dan semakin banyak parameter akan mempercepat proses clustering.

Perancangan aplikasi ini menggunakan metode waterfall yang mempunyai tahapan yang urut dan dapat masuk ke tahapan manapun ketika mau diperbaiki.Berdasarkan hasil pengujian black box testing diperoleh 96,4 \% dari ahli media dan responden $85,9 \%$.yang menyatakan aplikasi ini layak untuk digunakan. Aplikasi inimenyajikan deskripsi toko, foto produk, peta dan komentar.

\section{Ucapan Terima Kasih}

Penelitian ini didanai oleh DRPM DIKTI kategori Penelitian Kompetitif Nasional dengan skema Penelitian Dosen Pemula (PDP) dengan nomor kontrak KOPERTIS VI dengan LPPM : 34/K6/KM/SP2H/PENELITIAN/2018. Penulis ingin menyampaikan ucapan terima kasih kepada DRPM DIKTI yang telah memberi kesempatan dan dukungan dana yang cukup hingga selesainya penelitian ini.

\section{Daftar Pustaka}

Anwar, S.N., Nugroho, I., Supriyanto, E., 2015. Model Rute dan Peta Interaktif Posyandu di Kota Semarang Menggunakan Geolocation dan Haversine Berbasis Mobile Android, pp. 978979.

Badan Pusat Statistik Kabupaten Jepara., 2016. Kabupaten Jepara Dalam Angka 2016, Website: https://jeparakab.bps.go.id/. Diakses tanggal 09 Mei 2017.

Harwati, Alfiana, P.A., Wulandari, A.F., 2015. Mapping student's performance based on data mining approach (a case study) agriculture and agricultural. Science Procedia, (3): 173 - 177.

Kurniawan, Y., 2016. Monitoring dan Pemetaan UMKM Sektor Informal Kota Malang Berbasis Sistem Informasi Geografis.

Ong, J.O., 2013. Implementasi algotritma k-means clustering untuk menentukan strategi marketing president university. Jurnal Ilmiah Teknik Industri, vol.12, Eds Juni, 10-20.

Pascapraharastyan, 2015. Rancang bangun sistem informasi manajemen arsip rumah sakit bedah surabaya berbasis web. Jurnal Sistem Informasi, Vol 3. No. 139-143.

Santoso, B., 2007. Data Minning Teknik Pemanfaatan Data Untuk Keperluan Bisnis. Yogyakarta: Graha Ilmu.

Wakhidah, N., 2010. Clustering menggunakan kmeans algorithm (k-means algorithm clustering). Jurnal Transformatika, vol. 8 no. 1.

Wulandari, M.S., Noveandini, R., 2015. Digitalisasi Pemetaan UKM Tenun Garut Berbasis Sistem Informasi Geografis Sebagai Media Komunikasi dan Pemasaran Produk Lokal, 978-979. 